\title{
EVALUATION OF POST-OPERATIVE COMPLICATIONS FOLLOWING THYROID SURGERY
}

\author{
TALUKDER DC ${ }^{1}$, SARKER SC ${ }^{2}$, AHASAN SA ${ }^{3}$, HAQUE MM ${ }^{4}$, AREFIN MK ${ }^{5}$, MUSABBIR N ${ }^{6}$, \\ RHAMAN CMM ${ }^{7}$
}

\begin{abstract}
:
Objectives: This study evaluates the incidence, Frequency and risk factors of complications in patients submitted to thyroidectomy for various benign and malignant lesion and to corroborate the results in relation to the extent of surgery in a Tertiary level hospital.

Study design : An analytical study of 100 consecutive patients who underwent thyroidectomy for benign and malignant thyroid lesion.

Material s and methods: The study was carried out at Department of ENT and Head-Neck surgery in Dhaka Medical College Hospital over a period of 1.5 years from January 2017 to June 2018. Data were collected from 100 patients who underwent thyroidectomies for various thyroid diseases at this center.

Results: There were 80 females (80\%) and 20 males (20\%) with female-to-male ratio of 4:1, and The age range of the patients were 15 to 80 years, the mean age was 39.29 years. Preoperative diagnosis of benign and malignant pathologies was made in $86 \%$ and $14 \%$ cases respectively. Most common pathological diagnosis was colloid goiter 46\%,nodular of cases, whereas papillary carcinoma accounting for $11 \%$ was the commonest malignant lesion. The types of thyroid operations done were as follows (Table-II). The commonest operation performed was hemithyroidectomy (45\%). The overall postoperative complication rate was $17 \%$.Temporary and permanent RLNI occurred in 3\% and $2 \%$ respectively. The less common complications were wound hematoma, seroma formation, and superior laryngeal nerve injury. There was no mortality observed in this study.

Conclusion: In conclusion, extent of resection, surgical technique and thyroid pathologic condition had a greater impact on the rates of postoperative complications. By developing understanding of the anatomy and the ways to prevent each complication, the surgeon can minimize each patient's risk and can handle complications expediently and avoid worse consequence.
\end{abstract}

J Dhaka Med Coll. 2018; 27(2) : 108-113

\section{Introduction}

Thyroid gland disorders is the second most common endocrine disorders trailing diabetes mellitus. ${ }^{1}$ Surgical intervention can be required either benign or malignant tumor of thyroid gland. Other indications for thyroid surgery are the swelling or enlargement of thyroid in the form of nodular or colloid goiter orenlargement of thyroid gland causing breathing or swallowing difficulties. Thyroidectomy is also indicated in cases where an enlarged thyroid gland exhibits toxic symptoms, or where there is a high index of suspicion of malignancy, albeit cosmesis is the most common indication. ${ }^{2}$ The type of Thyroid surgery depends upon the Cytology of the lesion (benign or malignant features), size

1. Dr. Debesh Chandra Talukder, Associate Professor, Department of ENT \& Head Neck Surgery, Dhaka Medical College Hospital, Dhaka.

2. Dr. Satinath Chandra Sarker, Medical Officer, Department of ENT \& Head Neck Surgery, Dhaka Medical College Hospital, Dhaka

3. Dr. Syed Ali Ahasan, Medical Officer, Department of ENT \& Head Neck Surgery, Dhaka Medical College Hospital, Dhaka.

4. Dr. Muhammad Mozammal Haque, Registrar, Department of ENT \& Head Neck Surgery, Dhaka Medical College Hospital, Dhaka.

5. Dr. Mostafa Kamal Arefin, Medical Officer, Department of ENT \& Head Neck Surgery, Dhaka Medical College Hospital, Dhaka.

6. Dr. Nadira Musabbir, MD (Pediatric Gastroenterology) ,Outdoor Medical Officer, Department of ENT \& Head Neck Surgery, Dhaka Medical College Hospital, Dhaka.

7. Dr. Chowdhury Md. Mushfiqur Rahman, Assistant Professor, Department of ENT \& Head Neck Surgery, Dhaka Medical College Hospital, Dhaka.

Correspondence : Dr. Debesh Chandra Talukder, Associate Professor, Department of ENT \& Head Neck Surgery, Dhaka Medical College Hospital, Dhaka.

Received: 12 August 2018

Revision: 26 August 2018

Accepted: 08 September 2018

https://doi.org/10.3329/jdmc.v27i2.45819 
of the lesion, and degree of impairment,age,sex and nodal involvement. ${ }^{3}$

During the eighteenth century, the mortality rate of thyroid surgery was as high as $40 \%$ from hemorrhage and sepsis. ${ }^{4}$ The advent of modern antiseptic, anesthetic facilities and improved surgical techniques along with better hemostatic and surgical instrumentation during the last century has tremendously contributed to the very low morbidity and mortality rates of modern thyroid surgery. Major postoperative complications of thyroid surgeries include wound infection, hematoma/ hemorrhage causing airway compromise, hypocalcemia, recurrent or superior laryngeal nerve injury, and thyroid storm. Precise knowledge of the intricate anatomic details and meticulous surgical technique are prerequisite determinants for successful outcomes and to keep complications within acceptable limits. The aim of this study was to assess the incidence of different complications of various thyroid surgeries done for benign as well as malignant thyroid disorders in a tertiary care center and to compare it with published data with a brief overview of evolution of thyroid surgery.

\section{Materials and Methods}

The study was carried out at Department of ENT and Head-Neck surgery in Dhaka Medical College Hospitalduring the period from January 2017 toJuly 2018. This analytical study was done to assess complications after various types of thyroid surgeries indicated for benign as well as malignant thyroid lesions.

All patients diagnosed with Thyroid swelling were included. The criteria for selection of cases were mainly based on history, clinical examination, blood tests, neck ultrasound and fine needle aspiration cytology. sometimes special investigations like CT/MRI and X-ray were done for suspicious cases or where there was retrosternal extension.

Laryngeal endoscopy was done and documented in patients who developed hoarseness postoperatively. Vocal cord dysfunction existing after 6 months was labeled as a permanent paralysis. Serum calcium levels were measured on next postoperative day in all operated cases except isthmusectomy cases. Temporary hypoparathyroidism (HPT) was considered when total serum calcium level was less than $8.5 \mathrm{mg} /$ $\mathrm{dL}$ associated with muscle spasms, perioral numbness, and tingling sensation and which responded to exogenous calcium supplementation. Likewise, permanent HPT was considered when hypocalcemia persisted for more than 6 months despite regular calcium and vitamin D supplementation. The patients were followed up regularly for at least 6 to 9 months.

\section{Results}

During the study period, 100 patients presented with thyroid swelling and confirmed by various investigations. Only those, who were indicated for surgery were admitted into hospital.There were 80 females $(80 \%)$ and 20 males $(20 \%)$ with female-to-male ratio of $4: 1$, and The age range of the patients were 15 to 80 years, the mean age was 39.29 years. Preoperative diagnosis of benign and malignant pathologies was made in $86 \%$ and $14 \%$ cases respectively. Most common pathological diagnosis was colloid goiter $46 \%$ of cases, whereas papillary carcinoma accounting for $11 \%$ was the commonest malignant lesion (Table 1).

\section{Table-I}

Thyroid pathology observed in this study

\begin{tabular}{|c|c|c|}
\hline Pathology & Number & Percentage \\
\hline Colloid goiter & 46 & $46 \%$ \\
\hline Nodular/MNG & 34 & $34 \%$ \\
\hline Cyst & 2 & $2 \%$ \\
\hline Hyperplastic nodule & 4 & $4 \%$ \\
\hline $\begin{aligned} \text { Carcinoma } & \text { - Papillary } \\
& \text { - Follicular }\end{aligned}$ & $\begin{array}{c}11 \\
3\end{array}$ & $\begin{array}{l}11 \% \\
3 \%\end{array}$ \\
\hline
\end{tabular}

The types of thyroid operations done were as follows (Table II). The commonest operation performed was hemithyroidectomy (45\%). The overall postoperative complication rate was $17 \%$. Hypocalcemia were commonest complications noted in 7 cases followed by recurrent laryngeal nerve injury in 5 cases (Table III). 
Table-II

Type of thyroid operation performed

\begin{tabular}{lcc}
\hline Type of operation & $\begin{array}{c}\text { Noumber } \\
\text { of cases }\end{array}$ & Percentage \\
\hline Hemi thyroidectomy & 45 & $45 \%$ \\
Sub total thyroidectomy & 10 & $10 \%$ \\
Near-total thyroidectomy & 14 & $14 \%$ \\
Total thyroidectomy & 25 & $25 \%$ \\
(with or without neck & & \\
dissection) & & $6 \%$ \\
Isthmusectomy & 6 & \\
\hline
\end{tabular}

Table-III

Complications of thyroid surgery

\begin{tabular}{lcc}
\hline Complications & $\begin{array}{c}\text { Number } \\
\text { of cases }\end{array}$ & Percentage \\
\hline Temporary hypocalcemia & 4 & $5 \%$ \\
Permanent hypocalcemia & 3 & $3 \%$ \\
Temporary RLN injury & 3 & $3 \%$ \\
Permanent RLN injury & 2 & $2 \%$ \\
External LN injury & 3 & $5 \%$ \\
Hematoma formation & 1 & $1 \%$ \\
Seroma & 1 & $1 \%$ \\
\hline
\end{tabular}

All the injuries, whether temporary or permanent, were strictly unilateral. Temporary and permanent RLNI occurred in 3\% and $2 \%$ cases, respectively. Temporary paralysis occurred during surgery of two benign and one malignant lesion. With conservative management and speech therapy temporary paralysis recovered within 2 months after starting treatment. Permanent RLNI occurred in two cases of malignant lesion.Laryngoscopic examination was done postoperatively usually at 2nd or 3rd POD in every cases andduring follow up.Speech therapy given to two cases of permanent RLN injury in postoperative months. Lesion of external branch of superior laryngeal nerve were suspected in three (03) cases as they presented with classic symptoms of vocal fatigue and lowered voice tone and were endoscopically documented. Temporary hypocalcemia was seen in $4 \%$ of cases, whereas permanent hypocalcemia was observed in 3\% of all cases. During surgery sincere efforts were made to preserve at least two parathyroid glands. One patient developed postoperative hematoma and was reoperated on the 1st postoperative day due to internalhemorrhage ( Table 3). Complications according tothyroid pathologies are shown in Table-IV. Permanent hypocalcemia andpermanent RLNI both were most commonly observed in malignant cases while Temporary RLNI was the most common complication observed in cases operated for benign lesions.Complications for various types of thyroid surgeries are shown in Table 5. There was no operative mortality observed in this study. A total of eleven patients with thyroid malignancy were operated. Papillary carcinoma comprised the majority of cases. Extent of surgery ranged from Near Total Thyroidectomy to Total Thyroidectomy with central and lateral neck compartments neck dissection.. Wound infection after thyroid surgery was not observed in our study. None of the cases in our series was operated for hyperthyroidism. There was no postoperative mortality observed in our series.

Table-IV

Complications seen in surgery done for malignant and benign lesions

\begin{tabular}{lcc}
\hline Complications & $\begin{array}{c}\text { Surgery for } \\
\text { malignant } \\
\text { lesions }\end{array}$ & $\begin{array}{c}\text { Surgery for } \\
\text { benign } \\
\text { lesions }\end{array}$ \\
\hline Temporary hypocalcemia & 2 & 2 \\
Permanent hypocalcemia & 3 & \\
Temporary RLN injury & 1 & 2 \\
Permanent RLN injury & 2 & \\
External LN injury & 1 & 2 \\
Hematoma formation & & 1 \\
Seroma & & 1 \\
\hline
\end{tabular}

** RLN = Recurrent Laryngeal Nerve, LN = Laryngeal nerve 
Table-V

Complications seen in different thyroid surgeries

\begin{tabular}{lccccc}
\hline Complications & TT & NTT & STT & Hemithyroidectomy & Isthmusectomy \\
\hline Temporary hypocalcemia & 4 & & & & \\
Permanent hypocalcemia & 3 & & & & \\
Temporary RLN injury & 2 & 1 & & & \\
Permanent RLN injury & 2 & & & 1 & \\
External LN injury & 1 & & 1 & & \\
Hematoma formation & & & & & \\
Seroma & & & 1 & & \\
\hline
\end{tabular}

Table-VI

Causes of transient recurrent laryngeal paralysis

Injury due to electrocauterization

Damage due to excessive stretching

Excessive nerve skeletalization

Inflammation due to scarring and myelinic lesion Viral neuritis

A "frigore" or "calore" paralysis

\section{Discussion :}

There has been a significant reduction in the incidence of complication and mortality in thyroidsurgery,currently making thyroidectomy a surgical procedure with low acceptable morbidity and mortality rates. This is probably due to safer general anaesthesia, better antisepsis and the development of fine haemostatic instruments. ${ }^{5}$ Nonetheless; major complications of thyroid surgery (e.g., compressive haematoma, recurrent laryngeal nerve injury and hypoparathyroidism) are still fearful complications. The complications relating to damaged individual structures can be kept to a minimum by operating in a bloodless field and performing a meticulous anatomical dissection. ${ }^{6}$ More than a century ago, thyroid surgery had a reported mortality rate of $40 \%^{6}$. Death from thyroid surgery is extremely rare today .The overall postoperative complication rate in this study was $10.7 \%$ and no mortality was reported.The total rate of complications in our series was $17 \%$, which is in concordance with other studies, that is, 21 $\%{ }^{7}$ and $24 \%{ }^{8}$ Hematoma formation following thyroidectomy is a rare event occurring in Seroma formation, albeit not a serious complication of thyroidectomy, was noted in one patient.

Infections after thyroidectomies are reported as a rarity, and incidences have been noticed to be as low as 0.311 or $0.4 \%$ in various studies ${ }^{9}$. However, wound infection was not observed in any patient in our series. Patients in whom neck node dissection is planned along with thyroidectomy are prone to developing chylus leak, conservative management in the form of continuous drainage and measures aiming at reducing chyle production must be undertaken. ${ }^{10}$

Postoperative HPT is a serious issue leading to prolonged hospital stay and increased expenditure. ${ }^{11}$ The causation of postoperative HPT comprises various factors, with the surgical technique, the devascularization, and unintentional violation of the parathyroid glands being the most significant factors. ${ }^{12}$ Hypoparathyroidism (HPT) is considered when the calcium readings are below $7.5 \mathrm{mg} / \mathrm{dL}$ or less than $8.5 \mathrm{mg} / \mathrm{dL}$ if there are symptoms due to hypocalcemia; if the calcium level remained below $8.5 \mathrm{mg} / \mathrm{dL}$ at 1 year, it is considered permanent. ${ }^{12}$ Thesymptoms usually manifest 24 to 48 hours after surgery and occuras paresthesia and numbness over fingertips and perioral area and muscle cramps.Incidence of permanent Hypoparathyroidism was nil in benign disease and 3\% in malignant disorders operated in our series. In another study, the 
high incidence of Hypoparathyroidism after thyroidectomy for malignant cases was suggested due to malignant cases exposes risk to blood supply of parathyroids, particularly if done bilaterally, endangering their vascular supply, which eventually may increase chances of postoperative Hypoparathyroidism ${ }^{13}$.In majority of cases, hypothyroidism is not regarded as a complication of thyroid surgery. More suitably, it should be considered as an expected outcome. In cases of total or completion thyroidectomy, permanent thyroid insufficiency must be expected. ${ }^{14}$ Temporary and permanent RLN injury occurred in 3\% and $2 \%$ respectively in our study compare to Erbil at $a 1^{15}$ where post operativetempoorary recurrent laryngeal nerve palsy was found $6 \%$ and permanent was $5 \%$. The Sub Total Thyroidectomy may lessen the chances of developing postoperative hypothyroidism; nevertheless, the sound oncologic principles must not be jeopardized by the fear of permanent hypothyroidism. ${ }^{16}$ The incidence of postoperative hypothyroidism after Near Total Thyroidectomy in various studies has been reported to be 4422 to $46.3 \% .{ }^{17}$ In our series, hypothyroidism was observed only in cases who underwent Total Thyroidectomy.. Hypertrophic scarring or keloid formation is uncommon after thyroid surgery. No such complications were noted in our study .

\section{Conclusion :}

Conclusively, complications after thyroid surgery depend on patient's condition and presence of comorbidities, thyroid pathology, surgeon's expertise, and extent of surgery. Hypoparathyroidism and RLNI are the commonest complications observed after thyroidectomies. Attempts must be made to identify and preserve parathyroid glands to avoid HPT. It is of paramount importance for careful postoperative observation and timely intervention should the hypocalcemia develop and manifest. Similarly, recurrent and superior laryngeal nerve injury can be prevented by correctly identifying and following these nerves.

\section{References}

1. Tunbridge WM, Evered DC, Hall R, Appleton D, Brewis M, Clark F, Evans JG, Young E, Bird T, Smith PA. The spectrum of thyroid disease in a community: the Wickham survey. Clin Endocrinol (Oxf) 1977 Dec;7(6):481-493.

2. Abebe B, Mensur O. Goiter in a teaching hospital in North Western Ethiopia. East Afr J Surg 2006 Dec;11(2):21-27.

3. Shah JP. Thyroid and parathyroids. Shah, JP., editor. Head and neck surgery. New York: Mosby-Wolfe; 1996. p. 393-429.

4. Becker WF. Presidential address: pioneers in thyroid surgery. Ann Surg 1977 May;185(5):493-504.

5. Ramirez AT, Gibelli B, Tradati N, Giugliano G, Zurlo V, Grosso E, Chiesa F. Surgical management of thyroid cancer. Exp Rev Anticancer Ther 2007 Sep;7(9):1203-1214.

6. Slough, CM.; Johns, R.; Randolph, GW.; Lore, JM Jr.; Romanchisen, P. History of thyroid and parathyroid surgery. Randolph GW, editor. Surgery of the thyroid and parathyroid glands, 1 st ed. Philadelphia: Saunders; 2002. p. 3-11.

7. Zambudio AR, Rodriguez J, Riquelme J, Soria T, Canteras M, Parilla P. Prospective study of postoperative complications after total thyroidectomy for multinodular goiters by surgeons with experience in endocrine surgery. Ann Surg 2004 Jul;240(1): 18-25.

8. Rios A, Rodriguez JM, Canteras M, Garlindo PJ, Tebar FJ, Parilla P. Surgical management of multinodular goiter with compression symptoms. Arch Surg 2005 Jan;140(1): 49-53.

9. Akin M, Kurukahvecioglu O, Anadol AZ, Yuksel O, Taneri F. Analysis of surgical complications of thyroid diseases: results of a single institution. BratislLekListy 2009 Jan;110(1):27-30.

10. Frilling, A.; Weber, F. Complications in thyroid and parathyroid surgery. Oertli, D., Udelsman, R., editors. Surgery of the thyroid and parathyroid glands. 2nd edn. Berlin; London: Springer; 2012. p. 217-224.

11. Karamanakos SN, Markou KB, Panagopoulos K, Karavias D, Vagianos CE, Scopa CD, Fotopoulou V, Liava A, Vagenas K. Complications and risk factors related to the extent of surgery in thyroidectomy. Results from 2043 procedures. Hormones (Athens) 2010 Oct-Dec;9(4):318-325.

12. Reeve T, Thompson NW. Complications of thyroid surgery: how to avoid them, how to manage them, and observations on their possible effect on the whole patient. World J Surg 2000 Aug;24(8):971-975. 
13. Chow TL, Chu W, Lim BH, Kwok SPY. Outcomes and complications of thyroid surgery: retrospective study. Hong Kong Med J 2001 Sep;7(3):261-265.

14. Rosato L, Avenia N, Bernante P, De Palma M, Gulino G, Nasi PG, Pelizzo MR, Pezzullo L. Complications of thyroid surgery: analysis of a multicentric study on 14934 patients operated on in Italy over 5 years. World J Surg 2004 Mar;28(3):271-276.

15. Erbil Y, Barbaros U, Issever H, Borucu I, Salmasliođlu A, Mete O, Bozbora A, Ozarmađan S. Predictive factors for recurrent laryngeal nerve palsy and hypoparathyroidism after thyroid surgery. Clin Otolaryngol $2007 \mathrm{Feb}$;32(1):32-37.

16. Flynn MB, Lyons KJ, Tarter JW, Ragsdale TL. Local complications after surgical resection for thyroid carcinoma. Am J Surg 1994 Nov;168(5):404-407.

17. Miccoli P, Vitti P, Rago T, Iacconi P, Bartalena L, Bogazzi F, Fiore E, Valeriano R, Chiovato L, Rocchi $R$, et al. Surgical treatment of Graves' disease: subtotal or total thyroidectomy? Surgery 1996 Dec;120(6):1020-1025. 